\title{
Systematic review of early abortion services in low- and middle-income country primary care: potential for reverse innovation and application in the UK context
}

\author{
Jacy Zhou', Rebecca Blaylock ${ }^{2}$ and Matthew Harris ${ }^{1 *}$ (D)
}

\begin{abstract}
Background: In the UK, according to the 1967 Abortion Act, all abortions must be approved by two doctors, reported to the Department of Health and Social Care (DHSC), and be performed by doctors within licensed premises. Removing abortion from the criminal framework could permit new service delivery models. We explore service delivery models in primary care settings that can improve accessibility without negatively impacting the safety and efficiency of abortion services. Novel service delivery models are common in low-and-middle income countries (LMICS) due to resource constraints, and services are sometimes provided by trained, mid-level providers via "task-shifting". The aim of this study is to explore the quality of early abortion services provided in primary care of LMICs and explore the potential benefits of extending their application to the UK context.
\end{abstract}

Methods: We searched MEDLINE, EMBASE, Global Health, Maternity and Infant Care, CINAHL, and HMIC for studies published from September 1994 to February 2020, with search terms "nurses", "midwives", "general physicians", "early medical/surgical abortion". We included studies that examined the quality of abortion care in primary care settings of low-and-middle-income countries (LMICS), and excluded studies in countries where abortion is illegal, and those of services provided by independent NGOs. We conducted a thematic analysis and narrative synthesis to identify indicators of quality care at structural, process and outcome levels of the Donabedian model.

Results: A total of 21 indicators under 8 subthemes were identified to examine the quality of service provision: law and policy, infrastructure, technical competency, information provision, client-provider interactions, ancillary services, complete abortions, client satisfaction. Our analysis suggests that structural, process and outcome indicators follow a mediation pathway of the Donabedian model. This review showed that providing early medical abortion in primary care services is safe and feasible and "task-shifting" to mid-level providers can effectively replace doctors in providing abortion.

Conclusion: The way services are organised in LMICs, using a task-shifted and decentralised model, results in high quality services that should be considered for adoption in the UK. Collaboration with professional medical bodies and governmental departments is necessary to expand services from secondary to primary care.

Keywords: Abortion, Quality of service, Mid-level providers, Low-and-middle-income countries, Reverse innovation, UK

\footnotetext{
* Correspondence: m.harris@imperial.ac.uk

${ }^{1}$ School of Public Health, Imperial College London, London, UK

Full list of author information is available at the end of the article
}

C The Author(s). 2020 Open Access This article is licensed under a Creative Commons Attribution 4.0 International License, which permits use, sharing, adaptation, distribution and reproduction in any medium or format, as long as you give appropriate credit to the original author(s) and the source, provide a link to the Creative Commons licence, and indicate if changes were made. The images or other third party material in this article are included in the article's Creative Commons licence, unless indicated otherwise in a credit line to the material. If material is not included in the article's Creative Commons licence and your intended use is not permitted by statutory regulation or exceeds the permitted use, you will need to obtain permission directly from the copyright holder. To view a copy of this licence, visit http://creativecommons.org/licenses/by/4.0/ The Creative Commons Public Domain Dedication waiver (http://creativecommons.org/publicdomain/zero/1.0/) applies to the data made available in this article, unless otherwise stated in a credit line to the data. 


\section{Introduction}

In England and Wales, the criminalisation of abortion persists as a source of stigma, discrimination against women, and hinders provision of patient-centred clinical practices [1]. According to the 1967 Abortion Act, all abortions must be approved by two doctors, reported to the Department of Health and Social Care (DHSC), and can only be performed by doctors within licensed premises [2]. This legal framework causes accessibility issues, especially in rural communities lacking in both medical facilities and providers, and prevents the development of other innovative models, such as nurse/midwife-led surgical services [3]. The UK is unable to implement the WHO recommendation for services to optimise health worker roles in healthcare systems such as primary care because of the legal restrictions [4]. At the 1994 Cairo International Conference on Population and Development (ICPD), over 180 governments agreed that reproductive health care should be an integral part of primary health care and should be accessible in all countries "to all individuals of appropriate ages as soon as possible and no later than 2015" [5].

Several professional medical bodies, including the British Medical Association (BMA), the Royal College of Gynaecologists and Obstetricians (RCOG), and the Royal College of General Practitioners (RCGP) [6-8], advocate for the decriminalisation of abortion in England and Wales, stating that it will remove unnecessary barriers and improve the current clinical practice. Following recent successes in expanding sexual and reproductive rights in the Republic of Ireland and Northern Ireland, there is increasing pressure to decriminalise abortion in England and Wales $[9,10]$. This warrants the exploration of new service models which would be available after decriminalisation and could improve current practice.

In low-and-middle-income countries (LMICs), resource constraints motivate policymakers to rethink existing processes and make decisions that are cost effective [11]. Providers then leverage regulatory gaps to adopt "frugal innovations" [12]. Reverse innovation occurs when products/services that are highly effective and scalable penetrate marginalised markets of high-income countries (HICs); and for service models, core elements are extracted and adapted for local conditions [13].

Abortion services have long been part of primary care in LMICs and are sometimes "task-shifted" to mid-level providers (MLPs), such as nurses or midwives. Some studies from LMICs have shown that surgical abortions (SA) can be safely and effectively performed by MLPs in the primary care setting of LMICs $[14,15]$. The advent of early medical abortion $^{1}$ (EMA) has further enabled the provision of safe

${ }^{1}$ WHO recommends $200 \mathrm{mg}$ mifepristone administered orally, followed $1-2$ days later by $800 \mu \mathrm{g}$ misoprostol administered vaginally, sublingually or buccally [16]. abortion in a simple health facility with few requirements for technology or any surgical skills [17]. Understanding the potential value and challenges of reverse innovation for potential primary care abortion services in the UK is necessary to make strong evidence-based propositions for future policy and legislative changes [18].

In this article, we will:

- systematically review the evidence base for firsttrimester abortion services in primary care of LMICs,

- use a narrative synthesis approach to analyse the quality of abortion services with specific indicators organised around the Donabedian model,

- and consider the opportunities and challenges for the development of such services in the UK.

\section{Methods}

This systematic review was conducted using Covidence ${ }^{\mathrm{TM}}$ [19], and in accordance with the PRISMA Statement, refer to Additional file 1 [20].

\section{Search strategy and selection criteria}

We searched databases MEDLINE, EMBASE, Global Health, Maternity and Infant Care, Cumulative Index to Nursing and Allied Health Literature (CINAHL) and Health Management Information Consortium (HMIC) (grey literature database) for studies published between September $1994^{2}$ to February 2020 (Additional file 1: Full search strategy). All searches were limited to papers written in the English language. Other relevant papers were identified by citation searching and reference checking.

We used a $\mathrm{PI}(\mathrm{C}) \mathrm{OS}$ framework to establish search terms and selection criteria (Additional file 1: Search terms and selection criteria) [21]. The population was defined as all healthcare providers strictly in primary care settings, according to the WHO definition ${ }^{3}$ [22]. Studies in secondary and tertiary settings were excluded. NGO-led services were also excluded as they are semiautonomous and may be separate from formal healthcare systems depending on country. Population was further refined by country, including those classified as "low income," "lower-middle income," and "upper-middle income", and those where abortion is not entirely prohibited $^{5}$ (Additional file 1: List of LMICs) [23, 24].

\footnotetext{
${ }^{2}$ The chosen cut-off date as the 1994 Cairo International Conference on Population and Development (ICPD) was a turning point for sexual and reproductive health rights. Governments were urged to impose less punitive measures on women seeking abortion, provide safe abortion services and measures to manage complications resulting from unsafe abortions.

${ }^{3} \mathrm{WHO}$ defines primary care (PC) as the gate keeper to healthcare services and is where "first-contact, accessible, continued, comprehensive and coordinated care" occurs [22].

${ }^{4}$ According to the World Bank

${ }^{5}$ According to World Abortion Law
} 
The intervention was defined as early abortion (medical or surgical), where "early" implies a pregnancy under 12 weeks of gestation [25]. No comparators were considered as this review is an exploration of existing literature. The outcome was defined as the quality of abortion services, including themes outlined by Dennis et al. shown in Table 1 [26]. Only peer-reviewed primary studies were included. A list of excluded studies can be found in Additional file 1.

\section{Quality appraisal}

The quality of papers was assessed using a standardised checklist from the Mixed Methods Appraisal Tool (MMAT) 2018 [28]. This tool was chosen due to the heterogeneity of included papers. An extensive scoring guide and an overall quality score was given for each included study. A detailed assessment of each paper was also conducted, refer to Additional file 1.

\section{Data synthesis and analysis}

A narrative synthesis analysis was used due to the heterogeneity of included studies. JZ extracted the data using a standardised template and summarised the results narratively. RB was involved in identifying relevant themes and reaching a consensus on the data extracted.
A thematic analysis was conducted to assess the quality of abortion services according to various quality various indicators at the structural, process, and outcome levels. Table 1 shows the indicators of quality abortion care used in this study.

\section{Results}

Figure 1 shows the PRISMA flow diagram of this study [18]. An initial search yielded 3450 titles. Sixty-nine studies were selected for full-text review and an additional 21 studies were identified by forward and backward snowballing. We identified 18 studies for inclusion, of which there were eight implementation studies, three cross-sectional studies, three prospective cohort studies, two qualitative studies and two randomised controlled trials (RCT) (PRISMA diagram in Fig. 1). We describe the included study characteristics in Table 2 (see Additional file 1 for further details). Included studies were conducted in eight countries - Bangladesh [36], Democratic People's Republic of Korea (DPRK) [45], Ethiopia [30], India [31, 32, 37, 42], Kyrgyzstan [33], Nepal [29, 32, 35, 40, 41, 43, 44, 46], Nigeria [32, 38, 39] and South Africa [34].

With reference to Dennis et al. [26], we identified a total of 21 indicators to assess the quality of abortion services in eight subthemes, organised under three

Table 1 Indicators of high-quality early abortion care explored in this review, adapted from Dennis et al. [26]

\begin{tabular}{|c|c|c|}
\hline Theme & Subtheme & Indicators of high quality \\
\hline \multirow[t]{2}{*}{ Structure } & Law and Policy & $\begin{array}{l}\text {-Abortion care must be accessible and not limited by administrative or policy barriers. } \\
\text {-Regulations, guidelines and other policy documents have been developed, approved by national/sub-national } \\
\text { governments, and/or disseminated to health care facilities that are supportive of access to safe abortion care } \\
\text { consistent with WHO guidance. }\end{array}$ \\
\hline & Infrastructure & $\begin{array}{l}\text {-Efficient, high-quality referral systems are in place. } \\
\text {-Essential equipment, supplies and medications are available in sufficient quantity to address needs. } \\
\text {-Abortion is provided in a facility with space for privacy. }\end{array}$ \\
\hline \multirow[t]{4}{*}{ Process } & $\begin{array}{l}\text { Technical } \\
\text { Competency }\end{array}$ & $\begin{array}{l}\text {-Appropriate pain management techniques are in place. } \\
\text {-Physical assessments of general and sexual and reproductive health are performed (including confirmation of } \\
\text { gestational age). } \\
\text {-Staff follow approved guidelines and protocols for medical, surgical, and incomplete abortion. } \\
\text {-Staff use appropriate technologies. } \\
\text {-Follow-up care is provided, where client's experience with abortion and pregnancy status are assessed. }\end{array}$ \\
\hline & $\begin{array}{l}\text { Information } \\
\text { Provision }\end{array}$ & $\begin{array}{l}\text {-Staff explain all aspects of abortion care to clients (current condition, treatment plan, follow-up needs, and poten- } \\
\text { tial post-abortion complications and how to obtain appropriate post-abortion care). } \\
\text {-Staff provide clients the opportunity to express concerns, ask questions, and receive accurate, understandable } \\
\text { answers. }\end{array}$ \\
\hline & $\begin{array}{l}\text { Client-provider } \\
\text { interactions }\end{array}$ & $\begin{array}{l}\text {-Staff offer respectful care. } \\
\text {-Staff work to ensure privacy during the visit. } \\
\text {-Staff provide confidential care. } \\
\text {-Staff hold non-judgemental attitudes. } \\
\text {-Staff-client interactions promote an atmosphere of trust. }\end{array}$ \\
\hline & Ancillary Services & $\begin{array}{l}\text {-Staff directly provide or offer referrals for a range of sexual and reproductive health services, including } \\
\text { contraception and screening and treatment for HIV and STIs. }\end{array}$ \\
\hline \multirow[t]{2}{*}{ Outcome } & Abortion Outcomes & $\begin{array}{l}\text {-There is low number of admissions for treatment of abortion complications. } \\
\text {-There is a low percentage of maternal deaths as a result of abortion }{ }^{\text {a. }} \text {. }\end{array}$ \\
\hline & Client Satisfaction & - Clients are satisfied with abortion care \\
\hline
\end{tabular}

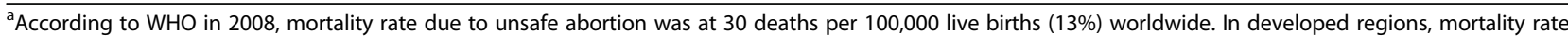
due to unsafe abortion was 0.7 deaths per 100,000 live births (4\%); in developing regions, mortality rate due to unsafe abortion was 40 deaths per 100,000 live births (13\%) [27] 


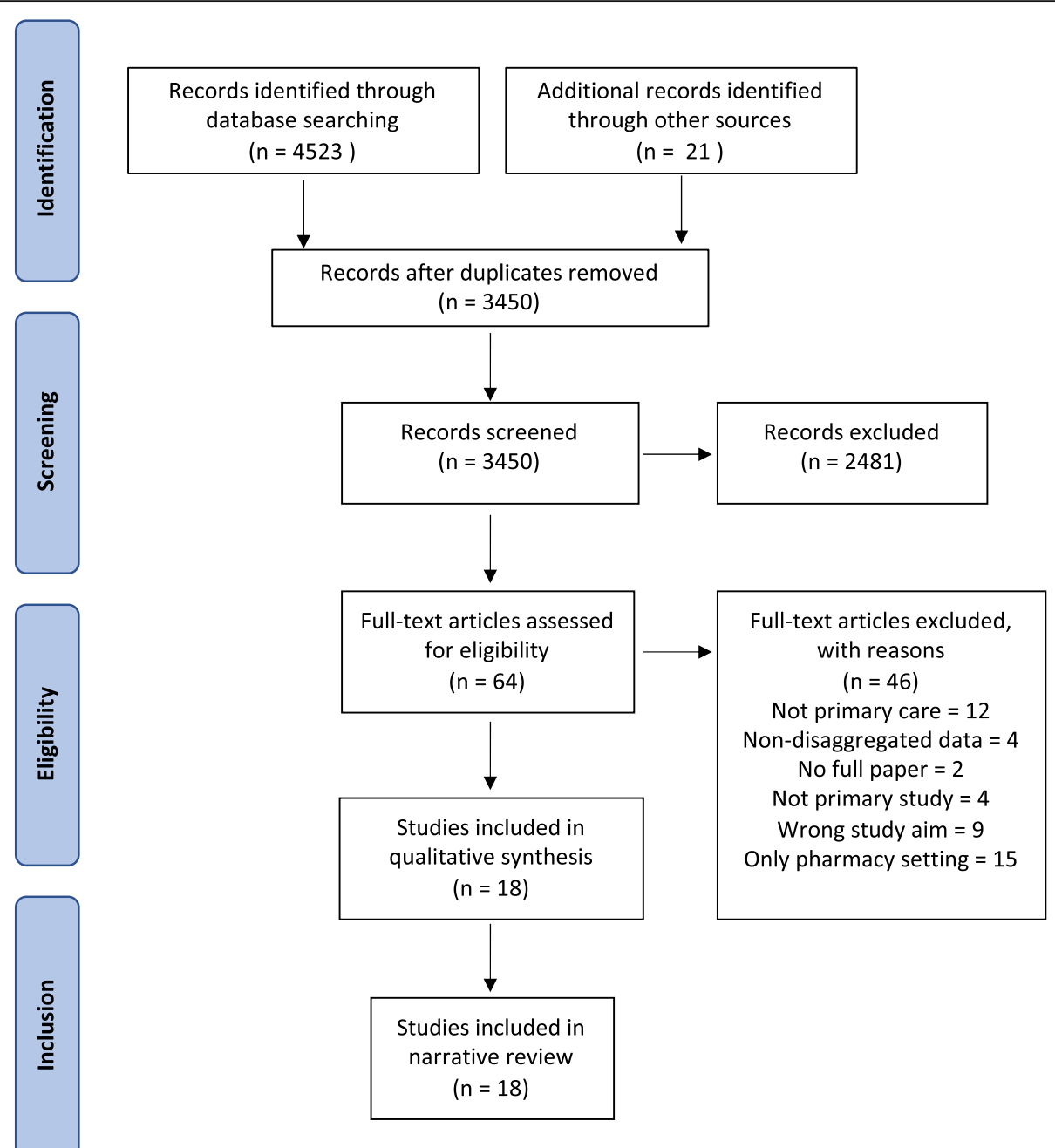

Fig. 1 PRISMA Flow Diagram

sections: (1) structural indicators: law and policy, infrastructure; (2) process indicators: technical competency, information provision, client-provider interactions, ancillary services; (3) outcome indicators: abortion outcomes, client satisfaction. The following is a narrative analysis of the abortion services and the contexts in which they operate, detailed in the included studies.

\section{Structural indicators}

\section{Law and policy}

LMICs are disproportionately affected by restrictive abortion laws, therefore unsafe abortions are extremely common in affected countries and result in high maternal mortality rates. In response to this phenomenon, the Bangladeshi government sanctioned "menstrual regulation" (MR), a

${ }^{6}$ It was introduced in 1979 as a procedure that regulates a woman's menstrual cycle when it has been absent for a short period of time. Legally less than 12 weeks from her last menstrual period. process to remove the uterine lining using surgical or medical methods, whether the woman is pregnant or not, henceforth enabling one to legally seek help through primary care services [40].

Liberal abortion policies encourage safe abortion services and reduce maternal mortality [47]. Countries (India, Ethiopia, Nepal, Kyrgyzstan, DPRK, South Africa) with liberal abortion law have well-established policies and guidelines for service provision [29-31, 33-35, 4046]. Nepal and Ethiopia have distinguished themselves from the rest, both adopting proactive and liberal measures to integrate medical abortion (MA) services in their local healthcare system by implementing national guidelines and task-shifting services to MLPs [29, 30, 32, $35,40,41,44,46]$ - but the results are vastly different. Nepal became a widely successful case and a regional leader of innovative abortion services while MA services are still lacking in Ethiopia - only 20.5\% of providers surveyed have received abortion training, and a majority 
Table 2 Summary of studies (Additional file 1: Detailed summary table)

\begin{tabular}{|c|c|c|c|c|c|c|c|}
\hline $\begin{array}{l}\begin{array}{l}\text { First author } \\
\text { (Year) }\end{array} \\
\end{array}$ & Country & $\begin{array}{l}\text { Abortion } \\
\text { legality }^{1}\end{array}$ & Provider & Training & $\begin{array}{l}\text { Sample } \\
\text { size }\end{array}$ & Study type (Description) & Quality $^{\mathrm{b}}$ \\
\hline $\begin{array}{l}\text { Andersen et al. } \\
\text { (2016) [29] }\end{array}$ & Nepal & 4 & $\mathrm{ANM}^{2}$ & Yes & 25,187 & $\begin{array}{l}\text { Implementation study (Site assessments, and quantitative } \\
\text { data collected on service provision and quality) }\end{array}$ & Medium \\
\hline $\begin{array}{l}\text { Assefa et al. } \\
\text { (2019) [30] }\end{array}$ & Ethiopia & 4 & $\begin{array}{l}\text { Nurse, Health } \\
\text { Officers, Midwives }\end{array}$ & No & 405 & Cross-sectional study (Structured questionnaires for MLPS) & High \\
\hline $\begin{array}{l}\text { Banerjee et al. } \\
\text { (2010) [31] }\end{array}$ & India & 3 & $\begin{array}{l}\text { Doctors (Majority } \\
\text { OB/GYN }{ }^{3} \text { ) }\end{array}$ & Yes & 60 & $\begin{array}{l}\text { Implementation study (Semi-structured questionnaire at } \\
\text { baseline and follow-up, and in-depth interview with doctors) }\end{array}$ & Medium \\
\hline $\begin{array}{l}\text { Benson et al. } \\
\text { (2017) [32] }\end{array}$ & $\begin{array}{l}\text { India, } \\
\text { Nepal, } \\
\text { Nigeria }\end{array}$ & $3,4,1$ & $\begin{array}{l}\text { Physicians, } \text { ANM }^{2} \text {, } \\
\text { midwives }\end{array}$ & Yes & 3435 & $\begin{array}{l}\text { Prospective cohort study (Questionnaires for providers at } \\
\text { baseline and follow-up over a 4-year period) }\end{array}$ & Medium \\
\hline $\begin{array}{l}\text { Johnson et al. } \\
\text { (2018) [33] }\end{array}$ & Kyrgyzstan & 4 & $\begin{array}{l}\text { Midwives and } \\
\text { family nurses }\end{array}$ & Yes & 554 & $\begin{array}{l}\text { Implementation study (Abortion outcomes of clients, and } \\
\text { questionnaires for clients at exit phase) }\end{array}$ & Medium \\
\hline $\begin{array}{l}\text { Kawonga et al. } \\
\text { (2008) [34] }\end{array}$ & $\begin{array}{l}\text { South } \\
\text { Africa }\end{array}$ & 4 & Did not specify & Yes & 290 & $\begin{array}{l}\text { Implementation study (Abortion outcomes of clients and } \\
\text { exit interview with clients. Qualitative interviews with } 5 \\
\text { providers) }\end{array}$ & Low \\
\hline $\begin{array}{l}\text { KC NP et al. } \\
\text { (2011) [35] }\end{array}$ & Nepal & 4 & $\begin{array}{l}\mathrm{ANM}^{2} \text { and senior } \\
\text { nurses }\end{array}$ & Yes & 1799 & $\begin{array}{l}\text { Implementation study (Abortion outcomes of clients and } \\
\text { interview on client's experience; and qualitative site } \\
\text { evaluation) }\end{array}$ & Medium \\
\hline $\begin{array}{l}\text { Marlow et al. } \\
\text { (2016) [36] }\end{array}$ & Bangladesh & 1 & Did not specify & N/A & 10 & $\begin{array}{l}\text { Qualitative study (in-depth interview to understand the } \\
\text { perspectives women's experience on medical abortion) }\end{array}$ & High \\
\hline $\begin{array}{l}\text { Mundle et al. } \\
\text { (2007) [37] }\end{array}$ & India & 3 & Doctors & Yes & 150 & $\begin{array}{l}\text { Implementation study (Abortion outcome of clients, } \\
\text { questionnaires on client experience and daily symptom diary } \\
\text { cards for clients) }\end{array}$ & High \\
\hline $\begin{array}{l}\text { Okonofua et al. } \\
\text { (2011) [38] }\end{array}$ & Nigeria & 1 & $\begin{array}{l}\text { Doctors (Mostly } \\
\mathrm{GP}^{8} \text { and } \mathrm{OB} / \\
\mathrm{GYN}^{3} \text { ) }\end{array}$ & No & 122 & Cross-sectional study (Structured questionnaires for doctors) & High \\
\hline $\begin{array}{l}\text { Okonofua et al. } \\
\text { (2005) [39] }\end{array}$ & Nigeria & 1 & $\begin{array}{l}\text { Doctors (Majority } \\
\mathrm{GP}^{8} \text { and } \mathrm{OB} / \\
\mathrm{GYN}^{3} \text { ) }\end{array}$ & No & 323 & Cross-sectional study (Structured questionnaires for doctors) & High \\
\hline $\begin{array}{l}\text { Puri et al. (2018) } \\
\text { [40] }\end{array}$ & Nepal & 4 & $\mathrm{ANM}^{2}$ & Yes & 605 & $\begin{array}{l}\text { Prospective cohort study (Structured questionnaire for } \\
\text { clients comparing the services in pharmacy vs. public health } \\
\text { facility) }\end{array}$ & Medium \\
\hline $\begin{array}{l}\text { Puri et al. (2014) } \\
\text { [41] }\end{array}$ & Nepal & 4 & ANM $^{2}$ & Yes & 241 & $\begin{array}{l}\text { Implementation study (Exit interviews with client, Semi- } \\
\text { structured interviews with ANMs) }\end{array}$ & Low \\
\hline $\begin{array}{l}\text { Ramachandar } \\
\text { and Pelto (2005) } \\
\text { [42] }\end{array}$ & India & 3 & $\begin{array}{l}\text { Doctors, nurses, } \\
\text { midwives, } \\
\text { pharmacists }\end{array}$ & No & 40 & $\begin{array}{l}\text { Qualitative study (in-depth interview with providers on } \\
\text { medical abortion) }\end{array}$ & Medium \\
\hline $\begin{array}{l}\text { Rocca et al. } \\
(2018)[43]\end{array}$ & Nepal & 4 & $\mathrm{ANM}^{2}$ & Yes & 605 & $\begin{array}{l}\text { Prospective cohort study (Structured questionnaire for } \\
\text { clients comparing the services in pharmacy vs. public health } \\
\text { facility) }\end{array}$ & High \\
\hline $\begin{array}{l}\text { Tamang et al. } \\
\text { (2017) [44] }\end{array}$ & Nepal & 4 & $\begin{array}{l}\text { ANM }^{2}+\text { staff } \\
\text { nurses (MLP) vs. } \\
\text { doctors }\end{array}$ & Yes & 1077 & $\begin{array}{l}\text { Randomised controlled trial (Exit survey "Acceptability form" } \\
\text { administered to ascertain women's experience) }\end{array}$ & High \\
\hline $\begin{array}{l}\text { Tran et al. } \\
(2010)[45]\end{array}$ & DPRK & 4 & Doctors & Yes & 199 & $\begin{array}{l}\text { Implementation study (Abortion outcomes of clients and } \\
\text { exit survey with clients) }\end{array}$ & High \\
\hline $\begin{array}{l}\text { Warriner et al. } \\
\text { (2011) [46] }\end{array}$ & Nepal & 4 & $\begin{array}{l}\text { ANM }^{2}+\text { staff } \\
\text { nurses (MLP) vs. } \\
\text { doctors }\end{array}$ & Yes & 1077 & Randomised controlled trial (Client abortion outcomes) & High \\
\hline
\end{tabular}

${ }^{\mathrm{b}}$ Quality was judged based on MMAT Critical Appraisal Tool - study methods were evaluated against the MMAT checklist, consisting 5 items (Additional file 1). High quality papers met at least 4 criteria; medium quality papers met 2 or 3 criteria; low quality papers met 1 criterion only. Refer to appendix for detailed evaluation of each criteria

1. Abortion legality: (1) To save woman's life only; (2) To save life, preserve physical and mental health; (3) To save life, preserve physical and mental health, and on socioeconomic grounds; (4) On request; 2. ANM: Auxiliary nurse-midwives; 3. OB/GYN: Obstetrician and Gynaecologists; 4. PCF: Primary care facility; 5. FOP: Felsher Obstetric Points; 6. PHC: Primary health centres; 7. HP: Health posts; 8. GP: General practitioner; 9. RHC: Reproductive health clinics; 10. District hospital is considered as part of its primary care in Nepal 
(71.6\%) felt uncomfortable working in a facility that provides abortion due to religious and personal reasons [30]. While a supportive government is necessary to introduce new policies, sociocultural factors such as religion and moral believes can hinder their success.

\section{Infrastructure}

Andersen et al. [29] reported a third of trained auxiliary nurse-midwives (ANMs) did not provide MA due to the lack of appropriate equipment and medication in Nepal. MA was rarely provided in Nigeria due to the high costs of drugs and tighter restrictions, but clinics were wellequipped to provide SA for incomplete abortions [38]. In South Africa, high medication cost was also a barrier to MA provision [34]. MA combination packs in India and Bangladesh made self-medication safer and more intuitive for women, expanding its access to local pharmacies [36, 37]. Some primary care clinics were unequipped to manage MA complications, but all studies detailed referral systems to secondary or tertiary care [29-46].

Privacy in facilities is essential to creating a safe environment for women, especially in communities where abortions are strongly associated with shame and discrimination. Three studies mentioned the lack of private space as an additional barrier to expanding MA services $[34,40,44]$. Yet, this was only made necessary in cohort studies and RCT studies [29, 32, 34, 35, 40, 41, 43, 44, 46]. No cross-sectional studies mentioned privacy, so its actual practice is lesser known. Only Andersen et al. reported the actual proportion of private rooms in their Nepal study $-71 \%$ in primary health centres and $53 \%$ in health posts [34].

\section{Process indicators}

\section{Technical competency}

MA is recommended by the $\mathrm{WHO}$ as a safe and effective method for abortion in the first trimester [25]. While MA becomes increasingly popular globally, surgical methods remain popular in Nigeria and India due to several reasons. (1) Providers have poor knowledge of MA regimen due to lack of training, i.e. most Nigerian doctors are only familiar with misoprostol as a drug for stomach ulcers as it is not licensed for MA [38, 39]; and India has non-standardised MA treatment as providers often rely on their intuition or personal experience to determine the "correct" dosage and regimen [37]. (2) High cost of medication was a barrier to accessibility, especially in rural areas of India with severe lack of funding [42]. (3) A resistance to change, as providers still prefer surgical methods for being marginally "quicker and easier", and less prone to complications compared to MA $[36,42]$. (4) The burden of responsibility placed on clients to self-manage their MA - hence providers may omit those who are uneducated (who may have difficulty comprehending instructions) and those living faraway (as heavy bleeding starts on the journey back home), as it can cause a greater inconvenience overall [36].

Several studies reported that nurses and midwives gained confidence with MA through ample training and practice, hence improving workflow $[29,32,33,35,40$, 41, 43, 44, 46]. Nevertheless, some suggested follow-up interventions to ensure long-term effectiveness, such as provider support networks and follow-up practice assessments [29, 35]. Several studies used an ultrasound scan to confirm gestational age of the pregnancy, but later have considered it unnecessary in most cases, consistent with WHO recommendations $[3,31,32,43,45$, 46]. Pain medication was provided to over $90 \%$ of clients in most cohort studies and RCT studies [40, 43, 45], but actual practice may be as low as $54 \%$, observed by Banerjee et al. in India [31].

\section{Information provision}

Ramachandar and Pelto [42] highlighted the importance of effective communication in MA as providers have less control over its outcome, relative to SA. This entails providing accurate and adequate information in a clear and concise manner to manage client expectations and reduce complications [40]. In several studies, providers were trained to brief clients on the procedure, side effects and complications of abortion [29, 31, 33-35, 37, 40, 41, 43-46]. However, actual practice largely depends on provider's knowledge and communication skills. Banerjee et al. [31] reported that $94 \%$ of providers explained the MA procedure to clients, $32 \%$ explained the possible side effects, and no providers counselled on complications. Some providers were unsure of what constituted a complication and had various ways of classifying expected effects such as pain and bleeding: "some doctors did not have clear idea of what's normal bleeding" [42]. Although studies reported a majority of their clients were at least "somewhat prepared" for the procedure in India and Kyrgyzstan, other studies in Nepal and Bangladesh show that some clients experience MA with unaddressed questions [33, 36, 41, 42].

\section{Client-provider interaction}

Clients in India and Nepal experienced judgement from providers and were treated with disrespect due to the stigma associated with abortion in some contexts [29, 37]. One provider restricted MA by the clients' social status and education level, believing urban clients can better comprehend the instructions [42]. Since selfmedication places a greater emphasis on client knowledge, selectively providing MA may reduce mismanagement, but may inadvertently deprive women in lower social status of MA, especially those in challenging situations, such as aborting without a partner's or family's 
consent. Providers who ensured confidentiality improved client's trust and comfort during the abortion process. In Nepal, the majority of clients valued the confidential support in clinics as they could receive abortion without informing their family members [41, 44]. Nurses/midwives-led services also improved trust and built strong rapport with women within local communities, as they were posted to each health stations longer than physicians $[29,35]$.

\section{Ancillary services}

Provision of contraception may be as low as $42 \%$, reported by Benson et al. across Nigeria, Nepal and India [32]. Short-term contraceptives such as condoms, pills and injectables are popular with clients, whilst longacting reversible contraceptives (LARC) such as intrauterine devices and implants are less popular [29, 32-44, 46]. One study claimed that given the poor accessibility to health facilities in rural areas, expanding the provision of LARC is important to prevent any unwanted pregnancies [34].

\section{Outcome indicators}

\section{Abortion outcomes and client satisfaction}

The majority of studies showed at least a 95\% complete abortion rate, consistent with the international benchmark [29, 33-36, 41, 45, 46, 48]. Only one study failed to meet $95 \%$, attributed to the provider's lack of experience with MA. All incomplete abortions were either resolved by surgical aspiration in the primary care clinic itself or through a referral to a hospital $[29,33-37,40$, $41,45,46]$. Most clients were satisfied with the abortion services they received and would recommend them to their friends [33, 35, 42, 45, 46]. Although satisfaction levels were subjective to clients, Tamang et al. [44] showed that high satisfaction rates were related to experiences of shorter length of abortion, a less-thanexpected amount of bleeding and high-quality counselling. SA outcomes were not investigated as cross-sectional studies did not allow for patient follow-up [38, 39].

\section{Discussion}

In this review, we explored the quality of first-trimester abortion services provided in primary care clinics of LMICs, using 21 indicators organised around the Donabedian model. In this service model, we observed an efficient workflow that optimised workforce while ensuring safety and client satisfaction. Compared to the classic linear relationship in a Donabedian's model, our results postulate a mediation pathway where good structure directly promotes good outcome and process, which in turn also promotes good outcome [49]. This pathway underscores the importance of structural components, but our review also showed that policies and infrastructure are insufficient - for example, in countries such as Ethiopia where pro-choice government policies do not necessarily result in accessible abortion services.

Many doctors in Nigeria and India still favoured SA, and some clinics were well-equipped to perform MVA in the event of incomplete abortion. We cannot comment on provider's competency and knowledge of SA as there was little evidence in the recent literature. As the worldwide trend changes from SA towards MA, our review shows that these components are essential for quality MA services: (1) a safe and private space to ensure client confidentiality for in-clinic abortion, due to its longer duration relative to SA; (2) a standardised understanding of arbitrary side effects, such as bleeding and pain; (3) a strong rapport between clients and providers as EMA focuses on self-medication.

Multiple studies also showed the success of taskshifting - nurses and midwives can effectively replace doctors in abortion services when well-trained and supported. Redistributing low-skilled tasks can optimise efficiency and improve work satisfaction across all providers, thereby combatting healthcare workforce shortages [13]. Passing tasks to midwives and nurses can also build a stronger rapport between provider and clients as they are sometimes able to commit to a local community in the longer-term [35]. Task-shifting is increasingly feasible with the popularity of MA as it requires less technical skills than SA [17]. Shifting the task to well-trained MLPs expands the provider network, thereby increasing service availability.

This review showed that provision of first trimester MA (EMA) in primary care services is safe, feasible and acceptable - decentralising abortion services to primary care and task-shifting will increase availability and accessibility. In the US, studies support the integration of EMA into its primary care system as it essentially uses skills that primary care providers already practice [50, 51]. Some countries, such as Australia, France, and the Netherlands, already provide EMA in primary care clinics [52-54]. In England and Wales, primary care teams in general practice (GPs) or sexual health clinics (SHCs) already provide counselling, pre-abortion screening, and referral into abortion services [55].

Former RCOG president, Anthony Falconer expects the line between primary and secondary women's healthcare to become fuzzier with more "gynaecological issues" resolved within the community, and the RCOG also proposed a "life-course approach" to women's health starting in primary care [56, 57]. In recent years, members of parliament across the House of Commons have shown overwhelming support for the decriminalisation of abortion [58, 59]. If this is achieved, EMA services will potentially expand to primary care and align with the NHS Long Term 
Plan, aimed at facilitating a stronger collaboration between primary and secondary care service for an integrated approach [60]. This expectation necessitates secondary-based trainings for primary healthcare practitioners to ensure technical competency. In RCOG's 2016 workforce survey of UK consultants, only 5.2\% (around $60 \%$ of OB/GYN specialists) included abortion as part of their work [61]. Expanding EMA services to GP clinics would increase the number of trained health professionals that perform simple abortion procedures, freeing up specialists for more urgent, complicated cases, such as those seeking abortion in later in pregnancy.

Nevertheless, some challenges need to be addressed while implementing change. Convincing stakeholders of the potential value that "frugal innovations", such as task-shifting, can bring to the NHS is complex. Innovations from LICs are often discounted or given shorter shrift, and research from these settings is rated worse based on their country of origin [62-64], complicating the diffusion of learning from these contexts. Nonetheless, the extensive experience of primary care EMA in these countries suggests that there is much that could be learned by the UK. There is a risk that introducing EMA into primary care in the UK may increase burden on GP clinics, already face issues of long-waiting hours and workforce shortages. Careful planning would be required to ensure that additional services do not result in a greater inefficiency and cost to the NHS.

\section{Strengths and limitations of study}

Our review had several limitations. First, a disproportionate number of MA papers were included thus less is understood on SA services in primary care due to a paucity of evidence. We also excluded services delivered in NGO clinics as they were not strictly primary healthcare - but are often similar in make-up to primary care clinics and sometimes, the sole providers of abortion services in some LMICs. Second, a majority of included studies were in a controlled environment, where provider practice was standardised by strict protocols therefore, results may not represent actual practice, and this also reflects a gap in the current literature as more cross-sectional studies should be conducted to give a full picture. Lastly, only two of the 18 studies were qualitative studies, but they contributed more insight in our review as their narrative form provides a deeper understanding of the phenomenon compared to quantitative studies.

\section{Conclusions}

Our review is the first to consolidate quality of abortion services provided in primary care clinics of LMICs. Using the Dennis et al. framework, we determined the components necessary for a successful abortion service in primary care clinics. Overall, we conclude that EMA provision in primary care is safe and feasible, and that implementing a similar service in the UK could improve access without compromising on quality.

The next steps would be a cost estimation of integrating an EMA service into GP clinics, and an economic evaluation to make a strong business proposition. Acceptability and feasibility studies would be required to explore the underlying conditions of primary care EMA. Qualitative studies would also provide an in-depth understanding of attitudes primary care providers and women have towards primary care EMA.

The recent COVID-19 outbreak further builds a strong case for changing policies to match the evidence base. Telemedical EMA was approved in England, Scotland and Wales, so women can now receive EMA at home, via nurse-led telephone consultations and medical abortion packs sent in the post [65]. The temporary approval of this service sets a precedent for abortion-service innovation, and moving forward, we believe implementing EMA in the UK primary care system can complement telemedical services to provide women with face-to-face care in their own community. We also further recommend that further research is conducted to inform and enable taskshifting of first trimester surgical abortions to nurses and midwives in UK primary care.

\section{Supplementary information}

Supplementary information accompanies this paper at https://doi.org/10. 1186/s12992-020-00613-z.

Additional file 1 Appendix S1.1. Medline Search Strategy (via Ovid) Appendix S1.2. EMBASE Search Strategy (via Ovid). Appendix S1.3. Global Health Search Strategy (via Ovid). Appendix S1.4. Maternal and Infant Care Search Strategy (via Ovid). Appendix S1.5: Health

Management Information Consortium Search Strategy (via Ovid). Appendix S1.6. CINAHL (via EBSCO). Appendix S2. PRISMA Checklist. Appendix S3. $\mathrm{PI}(\mathrm{C}) \mathrm{OS}$ Search Terms and Inclusion Criteria. Appendix S4. Detailed list of included papers. Appendix S5. Exclusion List. Appendix S6. Countries sorted on abortion law and income group. Appendix S7. Mixed Method Appraisal Tool (Quality Assessment)

\footnotetext{
Abbreviations

ANMs: Auxiliary nurse-midwives; BPAS: British Pregnancy Advisory Services; DHSC: Department of health and social care; DPRK: Democratic Republic of Korea; EMA: Early medical abortion; FOP: Felsher obstetrics point; GPS: General practitioners; ICPD: International Conference on Population and Development (ICPD); HICs: High-income countries; HP: Health post; LARCs: Long-acting reversible contraceptives; LMICs: Low-and-middle-income countries; MA: Medical abortion; MR: Menstrual regulation; MVA: Manual vacuum aspiration; MLPs: Mid-level providers; NGOs: Non-governmental organisations; NHS: National Health Services; OB/GYN: Obstetricians and gynaecologists; PCF/PHC: Primary care facility/Primary health clinic; RCGP: Royal College of General Practitioners; RCOG: Royal College of Gynaecologists and Obstetricians; RCT: Randomised controlled trials; RHC: Reproductive health clinics; SA: Surgical abortion; SHCs: Sexual health clinics; WHO: World Health Organisation
} 


\section{Acknowledgements}

We thank Dr. Patricia Lohr, Medical Director at British Pregnancy Advisory Service. Dr. Kate Whitehouse, Associate Director of Clinical Research and Development at British Pregnancy Advisory Service and Gillian Kane, Senior Policy Advisor at International Pregnancy Advisory Service, for comments on an earlier draft.

\section{Authors' contributions}

All authors were involved in study design, drafting of manuscript, providing comments and suggestions for the review. RB originated the study. $\mathrm{MH}$ and $\mathrm{RB}$ provided guidance on the framework and direction of the review. RB wrote and redrafted manuscripts and reviewed articles. JZ conducted literature searches, reviewed articles, wrote and drafted the manuscripts. The author(s) read and approved the final manuscript.

\section{Funding}

The authors received no funding for this article. $\mathrm{MH}$ is supported in part by the NW London NIHR Applied Research Collaboration. Imperial College London is grateful for support from the NW London NIHR Applied Research Collaboration and the Imperial NIHR Biomedical Research Centre. The views expressed in this publication are those of the authors and not necessarily those of the NIHR or the Department of Health and Social Care.

\section{Availability of data and materials}

Data used/analysed for this study are available from the corresponding author included in the review.

\section{Ethics approval and consent to participate}

Not applicable.

\section{Consent for publication}

Not applicable.

\section{Competing interests}

$\mathrm{RB}$ is the research and engagement lead at the British Pregnancy Advisory Services. MH is a non-executive director of Primary Care International.

\section{Author details}

${ }^{1}$ School of Public Health, Imperial College London, London, UK. ${ }^{2}$ British Pregnancy Advisory Service, London, UK.

Received: 3 July 2020 Accepted: 3 September 2020

Published online: 30 September 2020

\section{References}

1. Sheldon S. The decriminalisation of abortion: an argument for modernisation. Oxf J Leg Stud. 2016;36(2):334-65 https://doi.org/10.1093/ ojls/gqv026

2. Department of Health and Social Care. Abortion statistics for England and Wales: 2018. [Internet]. 2019. Available from: https:/www.gov.uk/ government/statistics/abortion-statistics-for-england-and-wales-2018 Accessed 2 Feb 2020.

3. Lee E, Sheldon S, Macvarish J. The 1967 Abortion Act fifty years on: Abortion, medical authority and the law revisited. Soc Sci Med. 2018;212: 26-32. Available from: https://www.sciencedirect.com/science/article/pii/S02 77953618303666 Accessed 2 Feb 2020.

4. World Health Organization, and UNAIDS. Safe abortion: technical and policy guidance for health systems. World Health Organization; 2003. Available from: https://www.who.int/reproductivehealth/publications/unsafe_ abortion/9789241548434/en/ Accessed 2 Feb 2020.

5. Nations $U$. Report of the international conference on population and development: Cairo 5-13 September 1994. New York: United Nations; 1995.

6. British Medical Association. Decriminalisation of abortion: a discussion paper from the BMA [Internet]. 2017. Available from: https://www.bma.org.uk/-/ media/files/pdfs/collective\%20voice/committees/arm/2017/bma-2017decriminalisation-of-abortion-discussion-paper.pdf?la=en Accessed 2 Feb 2020.

7. Royal College of Obstetricians \& Gynaecologists. RCOG backs decriminalisation of abortion; 2017. Available from: https://www.rcog.org.uk/ en/news/rcog-backs-decriminalisation-of-abortion/ Accessed 2 Feb 2020.
8. Royal College of General Practitioners. RCGP to support decriminalisation of abortion; 2019. Available from: https://www.rcgp.org.uk/about-us/news/201 9/february/rcgp-to-support-decriminalisation-of-abortion.aspx Accessed 2 Feb 2020.

9. British Broadcasting Company. Irish abortion referendum: Ireland overturns abortion ban; 2018. Available from: https://www.bbc.co.uk/news/worldeurope-44256152 Accessed 2 Feb 2020.

10. British Broadcasting Company. Northern Ireland to legalise abortion and same-sex marriage; 2019. Available from: https://www.theguardian.com/uknews/2019/oct/21/northern-ireland-set-to-legalise-abortion-and-same-sexmarriage Accessed 6 Sept 2020.

11. Crisp N. Chapter 5: Turning the world upside down. In: Commonwealth Secretariat. Commonwealth Health Ministers' Update 2010. Pro-Brook Publishing Limited. 2010. p.89-93. Available from: http://archives.enap.ca/ bibliotheques/2010/06/0301 10842.pdf Accessed 2 Feb 2020.

12. Govindarajan V., Trimble C. Reverse Innovation: create far from home, win everywhere. Boston, Massachusetts: Harvard Business Press; 2012

13. Ahmed F, Ahmed NE, Briggs TW, Pronovost PJ, Shetty DP, Jha AK Govindarajan V. Can reverse innovation catalyse better value health care? Lancet Glob Health. 2017;5(10):e967-e968. Available from: https:/www. thelancet.com/journals/langlo/article/PIIS2214-109X(17)30324-8/fulltext. Accessed 2 Feb 2020.

14. Jejeebhoy SJ, Kalyanwala S, Zavier AF, Kumar R, Mundle S, Tank J, Acharya R, Jha N. Can nurses perform manual vacuum aspiration (MVA) as safely and effectively as physicians? Evidence from India. Contraception. 2011;84(6): 615-21.

15. Warriner IK, Meirik O, Hoffman M, Morroni $C$, Harries J, Huong NM, Vy ND, Seuc AH. Rates of complication in first-trimester manual vacuum aspiration abortion done by doctors and mid-level providers in South Africa and Vietnam: a randomised controlled equivalence trial. Lancet. 2006; 368(9551): 1965-1972. Available from: https://www.ncbi.nlm.nih.gov/pubmed/17141 703 Accessed 2 Feb 2020.

16. World Health Organization. Medical management of abortion. World Health Organization; 2019.

17. Iyengar S.D. Introducing Medical Abortion within the Primary Health System: Comparison with Other Health Interventions and Commodities. Reprod Health Matt. 2005; 13(26): 13-19. Available from: https://www. tandfonline.com/doi/full/10.1016/S0968-8080(05)26217-1 Accessed 2 Feb 2020

18. Hadengue $\mathrm{M}$, de Marcellis-Warin $\mathrm{N}$ and Warin T. Reverse Innovation $\mathrm{A}$ Systematic Literature Review. Int J Emerg Mark, 2017, Vol. 12 Iss 2 pp. https://doi.org/10.1108/JoEM-12-2015-0272 Accessed 2 Feb 2020.

19. Covidence systematic review software, Veritas Health Innovation, Melbourne, Australia; 2016 Available at www.covidence.org.

20. Moher D, Liberati A, Tetzlaff J, Altman DG. Preferred reporting items for systematic reviews and meta-analyses: the PRISMA statement. Ann Internal Med. 2009; 151(4): 264-269. Available from: http://prisma-statement.org/ PRISMAStatement/Checklist.aspx Accessed 2 Feb 2020.

21. Tacconelli E. Systematic reviews: CRD's guidance for undertaking reviews in health care. Lancet Infect Dis. 2010; 10(4):226. Available from: https://www. thelancet.com/journals/laninf/article/PIIS1473309910700657/fulltext Accessed 2 Feb 2020.

22. World Health Organization. Primary healthcare. Available from: https:/www. who.int/news-room/fact-sheets/detail/primary-health-care Accessed 2 Feb 2020.

23. Center for Reproductive Rights. The World's Abortion Laws. Available from: https://reproductiverights.org/worldabortionlaws Accessed 2 Feb 2020.

24. World Bank Group. World Bank Country and Lending Groups. Available from: https://datahelpdesk.worldbank.org/knowledgebase/articles/906519world-bank-country-and-lending-groups Accessed 2 Feb 2020.

25. World Health Organisation (WHO). Clinical practice handbook for safe abortion. [Internet]. 2014. Available from: https://www.who.int/ reproductivehealth/publications/unsafe_abortion/clinical-practice-safeabortion/en/ Accessed 2 Feb 2020

26. Dennis A, Blanchard K, Bessenaar T. Identifying indicators for quality abortion care: a systematic literature review. J Fam Plann Reprod Health Care. 2017; 43(1):7-15. Available from: https://srh.bmj.com/content/43/1/7 Accessed 2 Feb 2020.

27. World Health Organisation. Unsafe abortion: Global and regional estimates of the incidence of unsafe abortion and associated mortality in 2008 (Sixth Edition). [Internet]. 2011. Available from: https://www.who.int/ 
reproductivehealth/publications/unsafe_abortion/9789241501118/en/ Accessed 2 Feb 2020.

28. Hong QN, Pluye P, Fàbregues S, Bartlett G, Boardman F, Cargo M, Dagenais P, Gagnon M-P, Griffiths F, Nicolau B, O'Cathain A, Rousseau M-C, Vedel I. Mixed Methods Appraisal Tool (MMAT), version 2018. Registration of Copyright (\#1148552), Canadian Intellectual Property Office, Industry Canada. Available from: http://mixedmethodsappraisaltoolpublic.pbworks. com/w/file/fetch/127916259/MMAT_2018_criteria-manual_2018-08-01_ENG. pdf Accessed 2 Feb 2020.

29. Andersen KL, Basnett I, Shrestha DR, Shrestha MK, Shah M, Aryal S. Expansion of Safe Abortion Services in Nepal Through Auxiliary NurseMidwife Provision of Medical Abortion, 2011-2013. J Midwif Women's Health. 2016;61(2):177-84. Available from: https://doi.org/10.1111/jmwh. 12419. Accessed 2 Feb 2020.

30. Assefa EM. Knowledge, attitude and practice (KAP) of health providers towards safe abortion provision in Addis Ababa health centers. BMC Womens Health. 2019;19(1):138.

31. Banerjee SK, Andersen K, Tank J, Parihar M, Shah M, Thanwala U. Evaluation of a network of medical abortion providers in two districts of Maharashtra, India. Glob Public Health. 2011;6(3):283-92. Available from: https://doi.org/ 10.1080/17441692.2010.516758. Accessed 2 Feb 2020.

32. Benson J, Healy J, Dijkerman S, Andersen K. Improving health worker performance of abortion services: an assessment of post-training support to providers in India, Nepal and Nigeria. Reprod Health. 2017; 14(1). Available from: https://doi.org/10.1186/s12978-017-0416-0. Accessed 2 Feb 2020.

33. Johnson BR, Maksutova E, Boobekova A, Davletova A, Kazakbaeva C, Kondrateva $Y$, et al. Provision of medical abortion by midlevel healthcare providers in Kyrgyzstan: testing an intervention to expand safe abortion services to underserved rural and periurban areas. Contraception. 2018;97(2): 160-6. Available from: https://doi.org/10.1016/j.contraception.2017.11.002. Accessed 2 Feb 2020.

34. Kawonga M, Blanchard K, Cooper D, Cullingworth L, Dickson K, Harrison T, Mollendorf C.V., Winikoff B. Integrating medical abortion into safe abortion services: experience from three pilot sites in South Africa. J Fam Plan Reprod Health Care. 2008;34(3):159-64. Available from: https://doi.org/10. 1783/147118908784734846. Accessed 2 Feb 2020.

35. KC NP, Basnett I, Sharma SK, Bhusal CL, Parajuli RR, Andersen KL. Increasing Access to Safe Abortion Services Through Auxiliary Nurse Midwives Trained as Skilled Birth Attendants. Kathmandu Univ Med J 2011; 36(4):260-266. Available from: http://akec.com.np/issue/36/260-266.pdf Accessed 2 Feb 2020.

36. Marlow HM, Biswas K, Griffin R, Menzel J. Women's experiences with medication for menstrual regulation in Bangladesh. Cult Health Sex. 2016; 18(3): 349-360. Available from: https://www.ncbi.nlm.nih.gov/pmc/articles/ PMC4732455/ Accessed 2 Feb 2020

37. Mundle S, Elul B, Anand A, Kalyanwala S, Ughade S. Increasing access to safe abortion services in rural India: experiences with medical abortion in a primary health center. Contraception. 2007;76(1):66-70. Available from: https://doi.org/10.1016/j.contraception.2007.03.010. Accessed 2 Feb 2020.

38. Okonofua FE, Hammed A, Abass T, Mairiga AG, Mohammed AB, Adewale A, et al. Private Medical Providers' Knowledge and Practices Concerning Medical Abortion in Nigeria. Stud Fam Plan. 2011;42(1):41-50. Available from: https://doi.org/10.1111/j.1728-4465.2011.00263.x. Accessed 2 Feb 2020

39. Okonofua FE, Shittu SO, Oronsaye F, Ogunsakin D, Ogbomwan S, Zayyan M. Attitudes and practices of private medical providers towards family planning and abortion services in Nigeria. Acta Obstet Gynecol Scand. 2005; 84(3):270-80. Available from: https://doi.org/10.1111/j.0001-6349.2005.00405.x. Accessed 2 Feb 2020.

40. Puri MC, Harper CC, Maharjan D, Blum M, Rocca CH. Pharmacy access to medical abortion from trained providers and post-abortion contraception in Nepal. Int J Gynecol Obstet. 2018;143(2):211-6. Available from: https://doi. org/10.1002/ijgo.12595. Accessed 2 Feb 2020.

41. Puri M, Tamang A, Shrestha $P$, Joshi D. The role of auxiliary nurse-midwives and community health volunteers in expanding access to medical abortion in rural Nepal. Reprod Health Matt. 2014;22(sup44):94-103. Available from: https://doi.org/10.1016/s0968-8080(14)43784-4. Accessed 2 Feb 2020.

42. Ramachandar L., Pelto P. J. Medical Abortion in Rural Tamil Nadu, South India: A Quiet Transformation. Reprod Health Matt. 2005;13(26):54-64. Available from: https://doi.org/10.1016/s-068-8080(05)26195-5. Accessed 2 Feb 2020 .
43. Rocca CH, Puri M, Shrestha P, Blum M, Maharjan D, Grossman D, et al. Effectiveness and safety of early medication abortion provided in pharmacies by auxiliary nurse-midwives: A non-inferiority study in Nepal. PloS One. 2018;13(1):e0191174. Available from: https://doi.org/10.1371/ journal.pone.0191174. Accessed 2 Feb 2020.

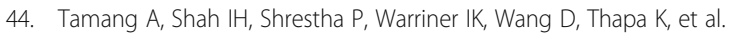
Comparative satisfaction of receiving medical abortion service from nurses and auxiliary nurse-midwives or doctors in Nepal: results of a randomized trial. Reprod Health. 2017;14(1). Available from: https://doi.org/10.1186/ s12978-017-0438-7. Accessed 2 Feb 2020.

45. Tran NT, Jang MC, Choe YS, Ko WS, Pyo HS, Kim OS. Feasibility, efficacy, safety, and acceptability of mifepristone-misoprostol for medical abortion in the Democratic People's Republic of Korea. Int J Gynecol Obstet. 2010; 109(3):209-12. Available from: https://doi.org/10.1016/j.ijgo.2010.01.012. Accessed 2 Feb 2020.

46. Warriner I., Wang D., Huong N.M., Thapa K., Tamang A., Shah I., et al. Can midlevel health-care providers administer early medical abortion as safely and effectively as doctors? A randomised controlled equivalence trial in Nepal. Lancet. 2011; 377(9772):1155-1161. Available from: https://doi.org/10. 1016/S0140-6736(10)62229-5 Accessed 2 Feb 2020.

47. Singh S, Remez L, Sedgh G, Kwok L, Onda T. Abortion worldwide 2017: uneven progress and unequal access. Available from: https://www. guttmacher.org/report/abortion-worldwide-2017 Accessed 6 Sept 2020.

48. Ngo TD, Park MH, Shakur H, Free C. Comparative effectiveness, safety and acceptability of medical abortion at home and in a clinic: a systematic review. Bull World Health Organ. 2011;89:360-70. Available from: https://doi. org/10.2471/BLT.10.084046 Accessed 6 Sept 2020.

49. Ameh S., Klipstein-Grobusch K., Musenge E., Kahn K., Tollman S., GómezOlivé F.X. Effectiveness of an integrated approach to HIV and hypertension care in rural South Africa: controlled interrupted time-series analysis. J Acquired Immune Def Syndromes. 2017; 75(4): 472-479. Available from: https://www.ncbi.nlm.nih.gov/pmc/articles/PMC5483981/ Accessed 2 Feb 2020.

50. Amico J.R., Cheng T.L., Godfrey E.M. Providing abortion Services in the Primary Care Setting. Women's health, An Issue of Primary Care: Clinics in Office. Elsevier-Health Science; 2018.

51. Yanow S. It is time to integrate abortion into primary care. Am J Public Health. 2013;103(1):14-6. https://doi.org/10.2105/ajph.2012.301119.

52. Family Planning NSW. Unplanned Pregnancy: Abortion [Internet]. 2019 Accessed 2 Feb 2020. Available from: https://www.fpnsw.org.au/factsheets/ individuals/abortion/unplanned-pregnancy-abortion.

53. Interruption Volontaire de Grossesse (IVG) Avortement prix. 2017 Accessed 2 Feb 2020. Available from: https://ivg.gouv.fr/avortement-prix.html.

54. Hardon A. Reproductive health care in the Netherlands: would integration improve it? Reprod Health Matters. 2003;11(21):59-73.

55. Royal College of Obstetricians and Gynaecologists. The Care of Women Requesting Induced Abortion: Evidence-based Clinical Guideline Number 7 [Internet]. 2011. Available from: https://www.rcog.org.uk/globalassets/ documents/guidelines/abortion-guideline_web_1.pdf.

56. Royal College Obstetricians and Gynaecologists. Better For Women, Improving the health and wellbeing of girls and women. London: Royal College Obstetricians and Gynaecologists; 2019. p. 15-6. Available from: https://www.rcog.org.uk/globalassets/documents/news/campaigns-andopinions/better-for-women/better-for-women-full-report.pdf.

57. Gerada C, Thompson R, Falconer A, Spyropoulos A, Bhugra D, Davies L, Bailey S. The NHS reforms: what they will mean for generalist and specialist clinicians. Br J Gen Pract. 2011;61(590):578-82.

58. British Pregnancy Advisory Services. Abortion rights are on the ballot this general election [Internet]. 2017. Available from: https://www.bpas.org/ about-our-charity/press-office/press-releases/abortion-rights-are-on-theballot-this-general-election/ Accessed 2 Feb 2020.

59. British Pregnancy Advisory Service. 50 years since 1967 Abortion Act passed, majority of MPs now have a more liberal position on abortion [Internet]. 2017. Available from: https://www.bpas.org/about-our-charity/ press-office/press-releases/50-years-since-1967-abortion-act-passedmajority-of-mps-now-have-a-more-liberal-position-on-abortion/ Accessed 2 Feb 2020.

60. Royal College of Obstetrician and Gynaecologist. Call for evidence on Abortion in the Developing World and the UK; 2018. Available from: http:// www.appg-popdevrh.org.uk/RCOG\%20Submission\%20APPG\%20PDRH\%2 0Abortion\%20UK.pdf. 
61. Lord Carter of Coles. Review of Operational Productivity in NHS providers: Interim Report June 2015. [Internet]. 2015. Available from: https:/assets. publishing.service.gov.uk/government/uploads/system/uploads/attachment_ data/file/434202/carter-interim-report.pdf Accessed 2 Feb 2020.

62. Tversky AM., Kahneman D. Judgment under uncertainty: Heuristics and biases. Science. 1974; 185(4157):1124-1131. Available from: https://science. sciencemag.org/content/185/4157/1124.short Accessed 2 Feb 2020

63. Harris M., Macinko J., Jimenez G., Mahfoud M., Anderson C. Does a research article's country of origin affect perception of its quality and relevance? A national trial of US public health researchers. BMJ Open. 2015; 5(12): e008993. Available from: https://doi.org/10.1136/bmjopen-2015-008993 Accessed 2 Feb 2020.

64. Harris M, Marti J, Watt $\mathrm{H}$, et al. Explicit Bias toward high-income country research: a randomised, blinded, crossover experiment in English clinicians. Health Aff. 2017:36:11.

65. Department of Health and Social Care. The Abortion Act 1967: Approval of a Class of Places [Internet]. 2020. Available from: https://assets.publishing. service.gov.uk/government/uploads/system/uploads/attachment_data/file/ 876740/30032020_The_Abortion_Act_1967_-_Approval_of_a_Class_of_ Places.pdf.

\section{Publisher's Note}

Springer Nature remains neutral with regard to jurisdictional claims in published maps and institutional affiliations.

Ready to submit your research? Choose BMC and benefit from:

- fast, convenient online submission

- thorough peer review by experienced researchers in your field

- rapid publication on acceptance

- support for research data, including large and complex data types

- gold Open Access which fosters wider collaboration and increased citations

- maximum visibility for your research: over $100 \mathrm{M}$ website views per year

At $\mathrm{BMC}$, research is always in progress.

Learn more biomedcentral.com/submissions 